\title{
Armazenamento a frio de ramos porta-borbulhas e métodos de enxertia de cultivares de marmeleiro
}

\author{
Cold storage of budsticks and grafting methods of quince cultivars
}

\author{
Viviane Marcela Celant ${ }^{\mathrm{I}}$ Rafael Pio ${ }^{\mathrm{II}}$ Edvan Alves Chagas ${ }^{\mathrm{III}}$ Ângelo Albérico Alvarenga ${ }^{\mathrm{IV}}$ \\ Idiana Marina Dalastra ${ }^{\mathrm{V}}$ Marcelo Angelo Campagnolo ${ }^{\mathrm{VI}}$
}

\section{RESUMO}

Visando a aumentar o aproveitamento do material propagativo, ampliar o período de oferta das mudas de marmeleiro e dinamizar o uso da mão-de-obra no viveiro, fazse necessário o armazenamento dos ramos porta-borbulhas. Sendo assim, o presente trabalho teve por objetivos estudar a viabilidade da manutenção dos ramos porta-borbulhas de diferentes cultivares de marmeleiro, por meio do armazenamento a frio, e diagnosticar o método de enxertia para promover melhor desenvolvimento do enxerto. Ramos dos marmeleiros 'Japonês' (Chaenomeles sinensis), 'Smyrna', 'Portugal', 'Mendoza Inta-37' e 'Provence' (Cydonia oblonga) foram coletados em julho de 2008. Uma parte dos ramos foi utilizada para a realização da enxertia (métodos de borbulhia e garfagem) em mudas de seis meses de idade do porta-enxerto 'Japonês', e a outra parte foi armazenada sob baixa temperatura (estacas envoltas em papel umedecido, embrulhadas em sacos de polietileno colocadas em câmara fria a $4^{\circ} \mathrm{C}$ ), por 30 e 60 dias. Passados 60 dias, foi mensurada a porcentagem de brotação dos enxertos e, ao final de 120 dias da realização das enxertias, foram mensurados o comprimento, o diâmetro e a massa seca média dos enxertos. Concluiu-se que, apesar de as cultivares apresentarem diferença, recomenda-se que os ramos sejam armazenados por até 30 dias, sendo utilizada a enxertia pelo método de garfagem.

Palavras-chave: Chaenomeles sinensis, Cydonia oblonga, produção de mudas.

\begin{abstract}
In order to increase the use of propagation material, enlarge the offer period of the quince seedlings production and dynamic use of the labor in the nursery, it becomes necessary to store the of budsticks. Thus, the present research aimed to study the feasibility of the maintaining budstick of different quince cultivars, through cold storage and to verify the grafting method to promote better development of the graft. Branches of the 'Japonês' (Chaenomeles sinensis), 'Smyrna', 'Portugal', 'Mendoza Inta-37' and 'Provence' (Cydonia oblonga) quince cultivars were collected in July, 2008. One of the branches was used for grafting (methods budding and cleft grafting methods) in 'Japonês' rootstock seedlings of six months of age and other part was stored at e low temperature (wrapped up cutting in humidified paper and wrapped up in polyethylene sacks, placed in cold chamber for $4^{\circ} \mathrm{C}$ ) for 30 and 60 days. After 60 days, the percentage of sprouting was measured and 120 days after grafting, the length, diameter and mass dries average of the grafts were measured. It was concluded that, despite the cultivars presented anydifference, it is recommended that the branches need to be stored for up to 30 days, if the cleft grafting is used.
\end{abstract}

Key words: Chaenomeles sinensis, Cydonia oblonga, seedlings production.

\section{INTRODUÇÃO}

A rusticidade comparada às demais frutíferas de clima temperado e a possibilidade de cultivo em

IUniversidade Estadual do Oeste do Paraná (UNIOESTE), Marechal Cândido Rondon, PR, Brasil.

IIUniversidade Federal do Paraná (UFPR), 80035-050, Curitiba, PR, Brasil. E-mail: rafaelpio@hotmail.com. Autor para correspondência.

IIIEmpresa Brasileira de Pesquisa Agropecuária (EMBRAPA CPAFRR), Boa Vista, RR, Brasil.

IVEmpresa de Pesquisa Agropecuária de Minas Gerais (EPAMIG/CTSM), Lavras, MG, Brasil.

vDepartamento de Produção Vegetal, Faculdade de Ciências Agronômicas de Botucatu, Universidade Estadual Paulista Júlio de Mesquita Filho (UNESP), Botucatu, SP, Brasil.

VIUniversidade Estadual do Oeste do Paraná (UNIOESTE), Marechal Cândido Rondon, PR, Brasil. 
praticamente todas as áreas que apresentam inverno ameno tornam o marmeleiro uma opção de cultivo interessante para muitos produtores que se dedicam à fruticultura, principalmente como alternativa para agricultura familiar em regiões turísticas, em razão da agregação de valores na transformação da polpa em doces e da escassez de marmeladas caseiras no mercado (PIO et al., 2005; ALVARENGA et al., 2007).

Recentemente, o marmeleiro 'Japonês'

(Chaenomeles sinensis Koehne) tem sido utilizado como opção de porta-enxerto devido ao elevado número de sementes por frutos (acima de 180), à alta germinação e à emergência das plântulas (acima de 90\% e 70\%, respectivamente) e à boa afinidade na relação enxerto/ porta-enxerto com algumas cultivares, como 'Provence', 'Portugal' e 'Mendoza Inta-37' (ALVARENGA et al., 2007; PIO et al., 2007). Os avanços tecnológicos da utilização de mudas enxertadas na marmelocultura foram altamente significativos, pois nem todas as cultivares de marmeleiro possuem bom potencial rizogênico (PIO et al., 2004). Além do mais, pomares implantados com mudas oriundas de estacas enraizadas possuem desenvolvimento inicial lento e com tendência em formar mudas "entouceradas" (excesso de brotações na base da planta) (ALVARENGA et al., 2007).

Para a produção de mudas enxertadas de marmeleiro, são coletados ramos porta-borbulhas junto à operação da poda, normalmente realizada no mês de julho, quando as plantas encontram-se em dormência (PIO et al., 2008). Como é uma prática rotineira e idêntica às demais frutíferas de clima temperado, há concentração dessa atividade nesse período, demandando muita mão-de-obra no viveiro e desfavorecendo o escalonamento da produção de mudas. Assim, faz-se necessário o armazenamento dos ramos porta-borbulhas, a fim de maximizar o aproveitamento do material propagativo, ampliar o período de oferta das mudas de marmeleiro e dinamizar o uso da mão-de-obra no viveiro.

Em citros, o armazenamento de ramos portaborbulhas em baixa temperatura já foi estudado e demonstrou ser uma técnica viável (MACIEL et al., 2008). O armazenamento em baixa temperatura, técnica que possui como finalidade ausentar o material propagativo de luz ou então suprir a necessidade de frio, tem como intuito superar a endodormência das gemas (BIASI, 1996). Nesse caso, pode-se ainda encurtar o período de formação das mudas e/ou obterem-se mudas com maior vigor, caso as gemas do enxerto brotem de forma antecipada.

Sendo assim, o presente trabalho teve por objetivos estudar a viabilidade do armazenamento a frio de ramos porta-borbulhas de diferentes cultivares de marmeleiro e diagnosticar o método de enxertia para promover melhor desenvolvimento do enxerto.

\section{MATERIAL E MÉTODOS}

Foram utilizadas sementes do marmeleiro 'Japonês', extraídas de frutos maduros coletados na Fazenda Experimental de Maria da Fé da EPAMIG Maria da Fé, Minas Gerais (MG), e armazenados em câmara fria por seis meses nas dependências da UNIOESTE, em Marechal Cândido Rondon, Paraná (PR). As sementes foram colocadas em placa de Petri entre camadas de algodão umedecido e estratificadas a frio em câmara fria, com temperatura de $4^{\circ} \mathrm{C}$, por 30 dias. Posteriormente, as sementes foram semeadas em bandejas de polipropileno (isopor) contendo vermiculita como substrato. Após 60 dias, as plântulas foram transplantadas para sacos plásticos com capacidade de 3L, contendo como substrato terra:areia:esterco de curral curtido (1:1:1 v/v). O substrato foi enriquecido com 191mg de superfosfato simples, 100mg de cloreto de potássio e $100 \mathrm{mg}$ de calcário por litro de substrato. Os porta-enxertos foram mantidos em viveiro constituído por tela de sombreamento, permitindo $50 \%$ de luminosidade e irrigados diariamente com regador manual. Após 150 dias do transplante, quando os porta-enxertos apresentavam diâmetro suficiente para a realização da enxertia, iniciou-se o experimento.

Ramos dos marmeleiros 'Japonês' (Chaenomeles sinensis), 'Smyrna', 'Portugal', 'Mendoza Inta-37’ e 'Provence' (Cydonia oblonga), padronizados com $20 \mathrm{~cm}$ de comprimento, foram coletados no mês de julho de 2008 (época da poda), no Centro APTA Frutas do Instituto Agronômico de Campinas (IAC), Jundiaí, São Paulo (SP). Uma parte dos ramos foi utilizada imediatamente para a realização da enxertia, a qual foi feita à altura de $20 \mathrm{~cm}$ acima do coleto do porta-enxerto. Os métodos de enxertia utilizados foram: 1) borbulhia tipo placa, em que as borbulhas foram amarradas com fita plástica transparente e, passados 30 dias, essas fitas foram retiradas e, em seguida, a parte aérea do porta-enxerto, acima da enxertia, foi decapitada; e 2) garfagem tipo fenda dupla, sendo utilizados garfos com três gemas e aproximadamente cinco centímetros de comprimento e os enxertos amarrados com fita plástica e protegidos por 30 dias com sacos plásticos transparentes $(15 \mathrm{~cm}$ de comprimento e $3 \mathrm{~cm}$ de diâmetro), com o intuito de formar uma câmara úmida e evitar a dessecação do material propagativo. Outra parte dos ramos foi armazenada a frio. Para o armazenamento, as estacas 
foram envoltas em papel umedecido, imersas em fungicida (Captan 500PM, na concentração $10 \mathrm{~g} \mathrm{~L}^{-1}$ ) por dois minutos, embrulhadas em sacos de polietileno e colocadas em câmara fria com temperatura de $4^{\circ} \mathrm{C}$ por 30 e 60 dias. Posteriormente, essas estacas foram utilizadas para a enxertia, pelos mesmos métodos descritos acima. Mensalmente, as mudas enxertadas receberam adubação com solução nitrogenada por cobertura (20g de ureia em 20L de água). Os enxertos foram conduzidos em haste única, sendo realizadas desbrotas periódicas.

O delineamento utilizado foi o inteiramente casualizado, em fatorial 3x2x5 (primeiro fator: tempo de armazenamento dos propágulos; segundo fator: tipo de enxertia; terceiro fator: cultivares de marmeleiro), com quatro repetições e 10 enxertos por parcela, totalizando 1.200 enxertos. Passados 60 dias, foi mensurada a porcentagem de brotação dos enxertos e, ao final de 120 dias da realização das enxertias, foram mensurados o comprimento $(\mathrm{cm})$ e o diâmetro médio (mm), cinco cm acima da brotação do enxerto, com auxílio de paquímetro digital. Em seguida, os enxertos foram removidos para a mensuração da massa seca média, por meio da secagem do material vegetal em estufa de circulação de ar forçado a $65^{\circ} \mathrm{C}$, durante 48 horas, e posterior pesagem em balança analítica, após apresentarem massa constante.

Os dados foram submetidos à análise de variância, e as médias foram comparadas pelo teste Scott-Knott, em nível de 5\% de probabilidade. Optouse em não realizar análise de regressão pelo fato de a curva apresentar apenas três pontos. As análises foram realizadas pelo programa computacional Sistema para Análise de Variância - SISVAR.

\section{RESULTADOS E DISCUSSÃO}

De acordo com a análise estatística, houve diferença para os fatores isolados em todas as variáveis em estudo. Houve ainda interação entre o tipo de enxertia e o tempo de armazenamento para todas as variáveis, interação entre o tipo de enxertia e as cultivares para o comprimento e diâmetro médio e, por fim, interação entre o tempo de armazenamento e as cultivares para a porcentagem de brotação e massa seca média. Não houve interação tripla entre os fatores.

Em relação ao tempo de armazenamento dos ramos porta-borbulhas e à posterior enxertia por garfagem, não houve diferença para o comprimento médio dos enxertos nos três períodos de armazenamento. No entanto, para as demais variáveis, somente houve diferença para os ramos armazenados por 60 dias, que propiciaram resultados inferiores (Tabela 1). Foi observado também que, aos 60 dias de armazenamento, os ramos já estavam praticamente todos calejados em suas bases, com possível iniciação rizogênica. Sendo assim, não é viável armazenar os ramos porta-borbulhas de marmeleiros por períodos superiores aos estudados no presente trabalho.

As enxertias pelo método de garfagem auxiliaram no maior desempenho em todas as variáveis analisadas, em comparação à borbulhia, independentemente do período de armazenamento dos ramos porta-borbulhas (Tabela 1). A porcentagem de brotação média dos três períodos de armazenamento para o método de garfagem foi de $90 \%$, propiciando incremento de $71,8 \%$ de brotação dos enxertos em comparação à média da enxertia por borbulhia nos três períodos. Resultados expressivos também ocorreram para o comprimento médio do enxerto (incremento de 29,3cm), o diâmetro médio (incremento de 2,3mm) e a massa seca média (incremento de 2,1g).

Tabela 1 - Porcentagem de brotação, comprimento médio, diâmetro médio e massa seca média de enxertos de cultivares de marmeleiro enxertadas pelos métodos de borbulhia e garfagem, oriundos de ramos porta-borbulhas armazenados a frio por diferentes períodos. Marechal Cândido Rondon-PR, UNIOESTE, 2009.

\begin{tabular}{|c|c|c|c|c|c|c|c|c|}
\hline \multirow{2}{*}{$\begin{array}{l}\text { Armazenamento } \\
\text { (dias) }\end{array}$} & \multicolumn{2}{|c|}{--------\% Brotação------- } & \multicolumn{2}{|c|}{----Comprimento (cm)---- } & \multicolumn{2}{|c|}{-----Diâmetro (mm)----- } & \multicolumn{2}{|c|}{-------Massa seca (g)------ } \\
\hline & Borbulha & Garfagem & Borbulha & Garfagem & Borbulha & Garfagem & Borbulha & Garfagem \\
\hline 0 & $3,5 \mathrm{Bc}$ & 96,0 Аа & $7,5 \mathrm{Bb}$ & 49,4 Аа & $0,9 \mathrm{Bb}$ & 5,3 Аа & $0,6 \mathrm{Bb}$ & 3,8 Аа \\
\hline 30 & $19,0 \mathrm{Bb}$ & 91,0 Аа & 24,9 Ba & 50,4 Аа & 3,3 Ba & 5,1 Аа & 2,4 Ba & 4,2 Аа \\
\hline 60 & 32,1 Ва & $83,0 \mathrm{Ab}$ & 24,1 Ва & 44,5 Аа & 3,5 Ва & $4,3 \mathrm{Ab}$ & 1,9 Ва & $3,2 \mathrm{Ab}$ \\
\hline CV (\%) & \multicolumn{2}{|c|}{19,67} & \multicolumn{2}{|c|}{17,88} & \multicolumn{2}{|c|}{15,13} & \multicolumn{2}{|c|}{9,01} \\
\hline
\end{tabular}

*Médias não seguidas pela mesma letra em maiúscula na linha e minúscula na coluna diferem entre si pelo teste Scott-Knott, a 5\% de probabilidade de erro. 
Esses resultados concordam com os de BARBOSA et al. (1998), os quais, trabalhando com a formação rápida de mudas vigorosas de pêra enxertadas em porta-enxerto oriental ('Taiwan Nashi-C'), verificaram que o processo de enxertia por garfagem propicia o desenvolvimento do enxerto com maior vigor, sendo obtidas mudas com maior tamanho e em tempo reduzido. Essas diferenças em relação aos métodos de enxertia estão relacionadas ao propágulo, já que os garfos possuem maior quantidade de reservas (carboidratos) em relação à borbulha, o que auxilia a cicatrização e brotação do enxerto. Esse resultado pode ser observado na tabela 2 , em que todas as cultivares de marmeleiro apresentaram maior comprimento e diâmetro médio dos enxertos quando enxertados pelo método de garfagem, os quais não diferiram entre si.

A época de realização e os métodos de enxertia encontram-se entre os fatores externos que afetam ou que podem afetar o desenvolvimento dos enxertos. Normalmente, espécies lenhosas caducifólias, como as frutíferas de clima temperado, apresentam ótimos índices de desenvolvimento quando os enxertos são realizados em período de repouso vegetativo e enxertados por garfagem (HARTMANN et al., 2002).

O porta-enxerto utilizado neste estudo proporcionou bom desenvolvimento para todas as cultivares de marmeleiro, quando enxertadas pelo método de garfagem. Após quatro meses da enxertia, todas cultivares apresentaram enxertos com mais de $40 \mathrm{~cm}$ de comprimento, estando aptos a serem levados ao campo. O interessante foi que os marmeleiros 'Provence', 'Mendoza Inta-37' e 'Portugal' apresentaram maior comprimento dos enxertos aos 120 dias, em relação aos resultados obtidos por PIO et al. (2008), os quais não armazenaram os ramos portaborbulhas e obtiveram mudas menores aos 150 dias após a operação de enxertia. Assim, é confirmada a hipótese de BIASI (1996), ressaltando que o armazenamento em baixa temperatura auxilia na superação da endodormência das gemas.

Essa hipótese fica mais evidenciada quando são observados os resultados da porcentagem de brotação dos enxertos (Tabela 3). As cultivares 'Japonês' e 'Mendoza Inta-37' tiveram maior porcentagem de brotação dos enxertos, quando os ramos porta-borbulhas foram armazenados por mais de 30 dias, e para o 'Smyrna', quando foram armazenados por 60 dias. No entanto, os enxertos do marmeleiro ‘Japonês' apresentaram maior acúmulo de massa quando foram armazenados por até 30 dias, do marmeleiro ‘Smyrna' quando armazenado por 30 dias e das demais cultivares de marmeleiro por 30 dias ou mais.

\section{CONCLUSÃO}

O armazenamento de ramos porta-borbulhas de marmeleiro é viável e favorece o escalonamento da operação de enxertia. Apesar de as cultivares apresentarem diferença, recomenda-se que os ramos sejam armazenados por até 30 dias. Após armazenamento, deve-se adotar a enxertia pelo método de garfagem.

Tabela 2 - Comprimento e diâmetro médio de enxertos de cinco cultivares de marmeleiro enxertadas pelos métodos de borbulhia e garfagem. Marechal Cândido Rondon-PR, UNIOESTE, 2009.

\begin{tabular}{|c|c|c|c|c|}
\hline \multirow[t]{2}{*}{ Cultivares de marmeleiro } & \multicolumn{2}{|c|}{ 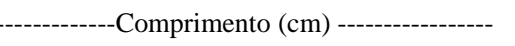 } & \multicolumn{2}{|c|}{ 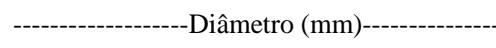 } \\
\hline & Borbulha & Garfagem & Borbulha & Garfagem \\
\hline 'Japonês' & $25,8 \mathrm{Ba}$ & $46,5 \mathrm{Aa}$ & $3,3 \mathrm{Ba}$ & 4,7 Аа \\
\hline 'Portugal' & $14,3 \mathrm{Bb}$ & 48,4 Аa & $1,8 \mathrm{Bb}$ & 4,9 Аа \\
\hline 'M. Inta-37’ & $27,6 \mathrm{Ba}$ & 53,5 Аa & 3,2 $\mathrm{Ba}$ & 4,9 Аа \\
\hline 'Provence' & $13,0 \mathrm{Bb}$ & 45,9 Аа & 2,3 Bb & 5,0 Аа \\
\hline 'Smyrna' & $12,5 \mathrm{Bb}$ & 46,2 Аа & 2,3 Bb & 4,9 Аа \\
\hline CV (\%) & \multicolumn{2}{|c|}{17,88} & \multicolumn{2}{|c|}{15,13} \\
\hline
\end{tabular}

*Médias não seguidas pela mesma letra em maiúscula na linha e minúscula na coluna diferem entre si pelo teste Scott-Knott, a 5\% de probabilidade de erro. 
Armazenamento a frio de ramos porta-borbulhas e métodos de enxertia de cultivares de marmeleiro

Tabela 3 - Porcentagem de brotação e massa seca média de enxertos de cinco cultivares de marmeleiro, oriundos de ramos porta-borbulhas armazenados a frio por diferentes períodos. Marechal Cândido Rondon-PR, UNIOESTE, 2009.

\begin{tabular}{|c|c|c|c|c|c|c|}
\hline \multirow[t]{2}{*}{ Cultivares de marmeleiro } & \multicolumn{3}{|c|}{-------------------------\% Brotação----------------------- } & \multicolumn{3}{|c|}{ 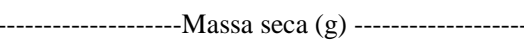 } \\
\hline & 0 & 30 & 60 & 0 & 30 & 60 \\
\hline 'Japonês’ & $53,7 \mathrm{Ba}$ & 65,0 Аа & $70,0 \mathrm{Aa}$ & 3,1 Аа & 3,7 Аа & $2,8 \mathrm{Bb}$ \\
\hline ‘Portugal’ & 46,2 Аа & $45,0 \mathrm{Ab}$ & $52,5 \mathrm{Ab}$ & $1,6 \mathrm{Bb}$ & $2,6 \mathrm{Ab}$ & $2,5 \mathrm{Ab}$ \\
\hline 'M. Inta-37' & $48,7 \mathrm{Ba}$ & 63,7 Аа & $63,7 \mathrm{Aa}$ & $2,5 \mathrm{Ba}$ & 3,7 Аа & 3,3 Аа \\
\hline 'Provence’ & 51,2 Аа & $52,2 \mathrm{Ab}$ & $43,7 \mathrm{Ab}$ & $1,9 \mathrm{Bb}$ & $2,9 \mathrm{Ab}$ & $2,6 \mathrm{Ab}$ \\
\hline ‘Smyrna’ & $48,7 \mathrm{Ba}$ & $48,7 \mathrm{Bb}$ & 61,5 Аа & $1,8 \mathrm{Bb}$ & 3,6 Аа & 2,1 Bb \\
\hline CV (\%) & & 19,67 & & & 9,01 & \\
\hline
\end{tabular}

*Médias não seguidas pela mesma letra em maiúscula na linha e minúscula na coluna diferem entre si pelo teste Scott-Knott, a 5\% de probabilidade de erro.

\section{REFERÊNCIAS}

ALVARENGA, A.A. et al. Marmelo (Cydonia oblonga Mill e Chaenomeles spp.). In: TRAZILBO, J.P.Jr.; MADELAINE V. (Org.). 101 culturas - Manual de tecnologias agrícolas. Belo Horizonte: EPAMIG, 2007. p.513-520.

BARBOSA, W. et al. Formação rápida de mudas vigorosas de pêra com porta-enxerto oriental. O Agronômico, v.47, p.2831, 1998.

BIASI, L.A. Emprego do estiolamento na propagação de plantas. Ciência Rural, v.26, n.2, p.309-315, 1996. Disponível em: $<$ http://www.scielo.br/scielo.php?script=sci_arttext\&pid=S0103$84781996000200025 \& \operatorname{lng}=p t \& n r m=i s o \& t \operatorname{lng}=p t>$. Acesso em: 23 jul. 2009. doi: 10.1590/S0103-84781996000200025.

HARTMANN, H.T. et al. Plant propagation: principles and practices. New Jersey: Prentice Hall, 2002. 880p.

MACIEL, H.S. et al. Viabilidade de borbulhas de citros coletadas de ambiente protegido e mantidas em frigoconservação. Revista Brasileira de Fruticultura, v.30, n.1, p.241-245, 2008. Disponível em: <http://www.scielo.br/scielo.php?script=sci_arttext\&pid=S010029452008000100044\&lng=pt\&nrm=iso >. Acesso em: 23 jul. 2009. doi: 10.1590/S0100-29452008000100044.
PIO, R. et al. Desenvolvimento de 31 cultivares de marmeleiro enxertadas no porta-enxerto 'Japonês. Revista Brasileira de Fruticultura, v.30, n.2, p.466-470, 2008. Disponível em: $<\mathrm{h}$ t $\mathrm{t}$ p : / / $\mathrm{w}$ w w. $\mathrm{s}$ c $\mathrm{i}$ e l o . b $\mathrm{r} /$ scielo.php? script=sci_art text \& pid=S $0100-$ $29452008000200034 \& \operatorname{lng}=p t \& n r m=i s o \& t \operatorname{lng}=p t>$. Acesso em: 23 jul. 2009. doi: 10.1590/S0100-29452008000200034.

PIO, R. et al. Emergência e desenvolvimento de plântulas de cultivares de marmeleiro para o uso como porta-enxertos. Revista Brasileira de Fruticultura, v.29, n.1, p.133-136, 2007. Disponível em: <http://www.scielo.br/scielo.php?script=sci_arttext\&pid=S010029452007000100029\&lng=pt\&nrm=iso\&tlng=pt $>$. Acesso em: 23 jul. 2009. doi: 10.1590/S0100-29452007000100029.

PIO, R. et al. Marmeleiro 'Japonês': nova opção de portaenxerto para marmelos. O Agronômico, v.57, p.15-16, 2005.

PIO, R. et al. Potencial de propagação de cultivares de marmeleiro por estacas. Revista Brasileira de Fruticultura, v.26, n.2, p.287-289, 2004. Disponível em: <http:// www.scielo.br/scielo.php?script=sci_arttext\&pid=S010029452004000200026\&lng=pt\&nrm=iso\&tlng=pt $>$. Acesso em: 23 jul. 2009. doi: 10.1590/S0100-29452004000200026. 